\title{
Defining international construction joint ventures from the Wittgenstein family-resemblance theory
}

\author{
Guzin Aydogan*iD \\ Mimar Sinan Fine Arts University, Faculty of Architecture, Istanbul, Turkey
}

\begin{abstract}
Joint ventures have been on the agenda of international contractors for the last few decades. Managing international construction joint ventures (ICJVs) and the performance of ICJVs has become the main subjects that researchers focused on after 2000. It is not possible to make the definition of ICJVs in a traditional way. That's why; the aim of this study is to make a contribution to the vague definition of ICJVs by using Ludwig Wittgenstein's family-resemblance theory as a method. Wittgenstein supposed that it is possible to understand a complex concept as a network of overlapping similarities. Researchers have applied Wittgenstein's family-resemblance theory to partnering, alliancing and relational contracting in construction. Similar to those studies, this study provides an innovative method to define vague concept of ICJVs by using Wittgenstein's idea of family resemblance theory. Components of ICJVs that were determined through an intensive literature review are used in this study in order to make a comprehensive definition. Finally, it was stated that combinations of these components differ to due cases after applying the sunflower model to three international aviation projects. The contribution of this innovative definition can be useful for both industrial practitioners and researchers, since it provides a flexible and structured way to discuss the multifaceted concept of ICJVs. In the procurement phase of an ICJV, professionals may use sunflower model in order to understand the differential dynamics of the venture. The model will also be a tool for defining the specific components of each venture and a common starting point for discussions between partners, thus avoiding any misinterpretations of what an ICJV is.
\end{abstract}

\section{Keywords}

International construction; Joint ventures; Definition; Components; Family-resemblance; Wittgenstein.

Received: 12 October 2020; Accepted: 21 December 2020

ISSN: 2630-5771 (online) (C) 2020 Golden Light Publishing All rights reserved.

\section{Introduction}

Organizations seek new strategies to become a global organization since late 1990's due to increasing competition in domestic market and globalization. Thus, entry strategies have become a critical concern on the firm's profitability and sustainability in global market. Market entry decision has been mentioned as one of the main research trends of international construction [1].
International joint ventures (IJVs) have become a popular strategy among firms whom wanted to enter new markets, grow and survive in global arena. IJVs have also become an appropriate entry mode for international contractors, since IJV is a strategy that allows achieving a temporary partnership between the participating firms in a project environment. Partners can find the opportunity to put-together their distinctive

\footnotetext{
* Corresponding author

Email: guzin.aydogan@msgsu.edu.tr
} 
competencies and complementary resources for the period of a project. This is the main motivation of firms that participate in a venture and stated as resource dependency theory in literature [2-4]. However, there are several other motivations that make firms to be a part of a venture. Entering a new market, strengthening relations with the host government, accessing local resources easily, gaining reputation during tendering, sharing project risks and decreasing the effects of environmental related risks are the other motivations of ICJVs.

Growing scales, complexities in construction, high levels of finance risks and uncertainty are the main parameters of international construction projects. International contractors participate in ICJVs in order to enter new markets as well as share risks and rewards in large scale-projects. International contractors establishing an ICJV are trying to fulfil their expertise in financing, engineering, procurement, and construction by sharing resources of their partners. Besides, participating firms collectively bid for and execute projects as they brought their diverse strengths and weaknesses together. ICJVs also allow sharing the risks related to the host country and conforming to the host government policies. The major construction projects in developing countries are often carried out in ICJVs with construction companies from developed countries in order to improve quality [5]. In addition, developing countries take ICJVs into account as a unique way of meeting the competing interests of national development and the prevention of the domination of the economy by foreign investors [6]. International contractors gain both competitive advantage and reputation in global market by participating in an ICJV. Within ICJVs, participating firms also share their responsibilities by functional separation and delegation of work [7]. Reducing risks, improving quality, reducing costs, completion on time and reducing work at the project level were mentioned as the direct benefits of ICJVs [8, 9]. Despite the aforementioned benefits of ICJVs, it is difficult to manage the formation and operation of ICJVs. ICJVs are complex to manage successfully due to diversification of partners' goals and cultural distance in a foreign country that has specific economic, political and socio-economic risks. Partner related, host country related and project related risks have effects on the overall performance of ICJVs [10]. Making a comprehensive definition of ICJVs concerning core and non-core components is necessary, since organizations improve their competitive position, learn from the other participant and perceive sufficient benefits in relation to costs through successful venture operations. Hence, it is necessary to understand the fundamental definition of a Joint Venture. A Joint venture (JV) was identified as an independent legally separate entity including at least two partner organizations that contribute resources in equity by [11]. In addition, Geringer and Herbert [12] defined an IJV as a form of JV if at least one of the participating firms is headquartered outside the venture's country of operation. This basic definition refers to an overall view of the IJVs. However, IJVs include different performance characteristics components due to the diversification of industries and environmental factors. Considering international construction; Girmscheid and Brockmann [7] stated the marked difference of IJVs and ICJVs. ICJVs are contractual joint ventures or agreements whereas IJVs mostly refer to equity joint ventures [13]. Besides, JVs in construction can be categorized into two types including; integrated and non-integrated [14]. Integrated type of a venture refers to a single project team formed by the staff of participating firms where non-integrated venture allows partners to be responsible of the work that is on their liability.

These contributions to define ICJVs only refer to a categorization based on the contractual agreement and the responsibilities of the project team but a comprehensive definition of ICJVs is still missing. There are several components of ICJVs that has effects on the overall performance of ventures. That's why; a comprehensive definition of ICJVs must include these components. Components of ICJVs vary according to the project, partners and the environmental factors. That's why; the first step towards a clearer conception of ICJVs 
is recognizing that such a basic definition does not fit in with this multifaceted concept. It is not possible to discuss different projects with the same performance characteristics since components of ICJVs differ due to project, partners and environmental factors. Besides; two people having different objectives discuss the definition of an ICJV by using different sets of components. That's why; making a definition of ICJVs concerning all components will be useful since IJV is a common relational contracting system used by international contractors for the last three decades.

Realizing the need for a common perception, the main objective of this study is to make a new contribution to the vague definition of ICJVs by applying Wittgenstein's family-resemblance theory. Performance characteristics of ICJVs were determined through an intensive literature review by a previous study [15]. Based on the findings of this previous study, determined performance characteristics named as the components of ICJVs. These components were used in order to make a definition of ICJVs by applying familyresemblance theory. In the forthcoming parts of this paper, after defining Wittgenstein's familyresemblance theory and the core components of ICJVs, the application of this model in defining ICJVs will be explained in detail. Finally, the definition of ICJV based on family-resemblance theory will be applied in three cases by focussing on core and non-core components.

\section{Wittgenstein's family-resemblance theory}

ICJVs were usually defined as a special type of strategic alliance; leading competitive advantage in global market by combining distinctive competencies and complementary resources of participating contractors. The definition of IJVs by Geringer and Herbert [12] was also mentioned in studies concerning ICJVs. But it is clear that there is no consensus on the definition of ICJVs based on specific components. Therefore, the concept appears vague.

The German philosopher Ludwig Wittgenstein would disagree and argue that concepts including confusing aspects cannot be defined in the traditional way depending only on essential and adequate conditions. In fact, these complicated concepts might include increasing numbers of aspects that are common for all variants of a term. That's why; it is not possible to define these complicated concepts in the traditional way. Stating this point of view, Wittgenstein argued that there are complex networks of overlapping similarities among the things that fall under a complex concept [16]. He explained this by taking the term GAME as an example. He stated that there are a large number of activities characterized as games but there is not a single and common feature concerning all of them. Although ball games such as basketball and tennis have rules to follow, there are no rules stated clearly when a boy just throws the ball in the air. Compared to board games; there are common characteristics such as rules and competitiveness but some elements such as hard physical work and the ball are missing. Consequently, Wittgenstein suggested that all types of games including different characteristics can be defined in a complex network of features. Such an approach to understand a concept with many different aspects came to be called family-resemblance as it resembles the similar features that can be found within a family. The daughter in a family could have the 'same' nose as her mother, while the mother and the son have the 'same' eyes, but there is no feature common to all members of the family. However, a bond between them still exists $[16,17]$ cited in [18].

Wittgenstein's theory of family-resemblance theory enables to make a comprehensive definition of a complex term since it doesn't limit the aspects of a concept. Consequently, this approach has found to be useful by researchers in understanding terms that cannot be defined in the traditional way. Researchers have used Wittgenstein's familyresemblance theory as a method for defining vague concepts in construction management. First, Nyström [18] used Wittgenstein's familyresemblance theory in defining partnering concept in construction. Following Nyström [18], Yeung et al. [19], applied family-resemblance theory to make a comprehensive definition of alliancing in construction. In the following years, Yeung et al. 
[20], also defined relational contracting by using family-resemblance theory. Similar to those studies, this study makes a new contribution in making a comprehensive definition of ICJVs by applying Wittgenstein's family-resemblance theory.

\section{Literature review}

International construction is one of the main research areas of construction management literature and ICJVs have gained the attention of researchers. Risks; risk assessment models [21-24], management issues [7, 9, 25-28] and performance characteristics; performance models of ICJVs [6, 10, 29-34] are the main research areas of ICJVs. Thus, a research focussing on the definition of ICJVs has not been developed.

Concerned with making a comprehensive definition of ICJVs by using family resemblance theory, components of ICJVs should be included in the network of overlapping features. That's why; identifying the components of ICJVs is the first step of this study. Components of ICJVs are presented in Table 1 based on a previous study by [15]. Aimed on determining performance characteristics of ICJVs, this previous study covers an intensive literature review both in management science and construction management literature. Table 1 is adapted from this previous study. By using meta analysis technique, $A(\sqrt{ })$ in Table 1 shows that the author has mentioned this component as an aspect of international venturing concept. Nineteen components of ICJVs in total were determined through literature review where nine of these were found to be core components due to the rankings. According to the analysis of thirty-nine papers; rankings of core components of ICJVs are presented in Table 2.

It is possible to categorize the core components of ICJVs in three main issues including; partner related issues, management related issues and environmental related issues. Core components of ICJVs will be explained concerning these issues in the following parts of this study. After discussing the core components of ICJVs, family resemblance theory will be applied to make a comprehensive definition of ICJV. This approach is a way of development of a structure among the components in discussing the definition of ICJVs based on three cases including; Riyadh King Khalid Airport Project, Katar Hamad International Airport Project, and Paris-Charles de Gaulle Airport Management Buildings.

\subsection{Core components of partner related issues}

Construction projects are highly complex and hard to manage due to fragmentation, and risks. International construction projects that are carried out by a venture concern some other challenges due to inter-partner relationship, venture management and environmental risks. Partner selection follows the decision of entering into a new market by establishing a venture. The core components of ICJVs related to partner are high in number than the core components related to venture management and the core components related to host country (Table 2). That's why; it is obvious that partner related issues have a high importance on the overall performance of ICJVs and selecting an appropriate partner is very important [35]. Trust, clear identification of partners' goals, mutual commitment, partner competence, compatibility of partners' management culture, and cooperation are found to be the core components of partner related issues affecting the performance of ICJVs due to literature review.

Trust has found to be the most important component of ICJVs with the highest ranking among other core components that are partner related. In some cases development of trust takes time, but sometimes it may appear based on reputation or spontaneously. Partners' whom have participated in a previous venture expected to have good relations in the following organizations. However, Gulati [36] has stated that prior relations between partners sometimes could sow distrust instead trust. Trust and mutual commitment were the prominent components of IJVs that researchers focussed on $[37,38]$. 
Table 1. Components of ICJVs (Aydogan [15])

Yeung et al. 2012

Ozorhon et al. 2011

Ozorhon et al. 2010

Girmscheid \& Brockmann 2010

Ho et al. 2009

Ozorhon et al. 2008a

Ozorhon et al. 2008b

Ozorhon et al. 2007a

Zhang \& Zou 2007

Ozorhon et al. 2007b

Sillars \& Kangari 2004

Gale \& Luo 2004

Mohamed, 2003

Chan \& Tse 2003

Walker \& Johannes 2003

Fisher \& Ranasinghe 2001

Luo, 2001

Kwok and Walker 2000

Norwood and Mansfield 1999

Ramaseshan and Loo, 1998

Tatoğlu \& Glaister, 1998

Glaister \& Buckley, 1998

Lane et al., 2001

Zhang \& Li, 2001

Yan \& Gray, 2001

Luo, 2002

Boateng and Glaister, 2002

Child 2002

Zeybek et al. 2003

Choi and Beamish, 2004

Kwon, 2008

Fang \& Zou, 2009

Reus \& Rottig, 2009

Pak et al., 2009

Ren et al., 2009

Beamish \& Lupton 2009

Merchant, 2012

Nemeth \& Nippa, 2013

Park et al. 2015
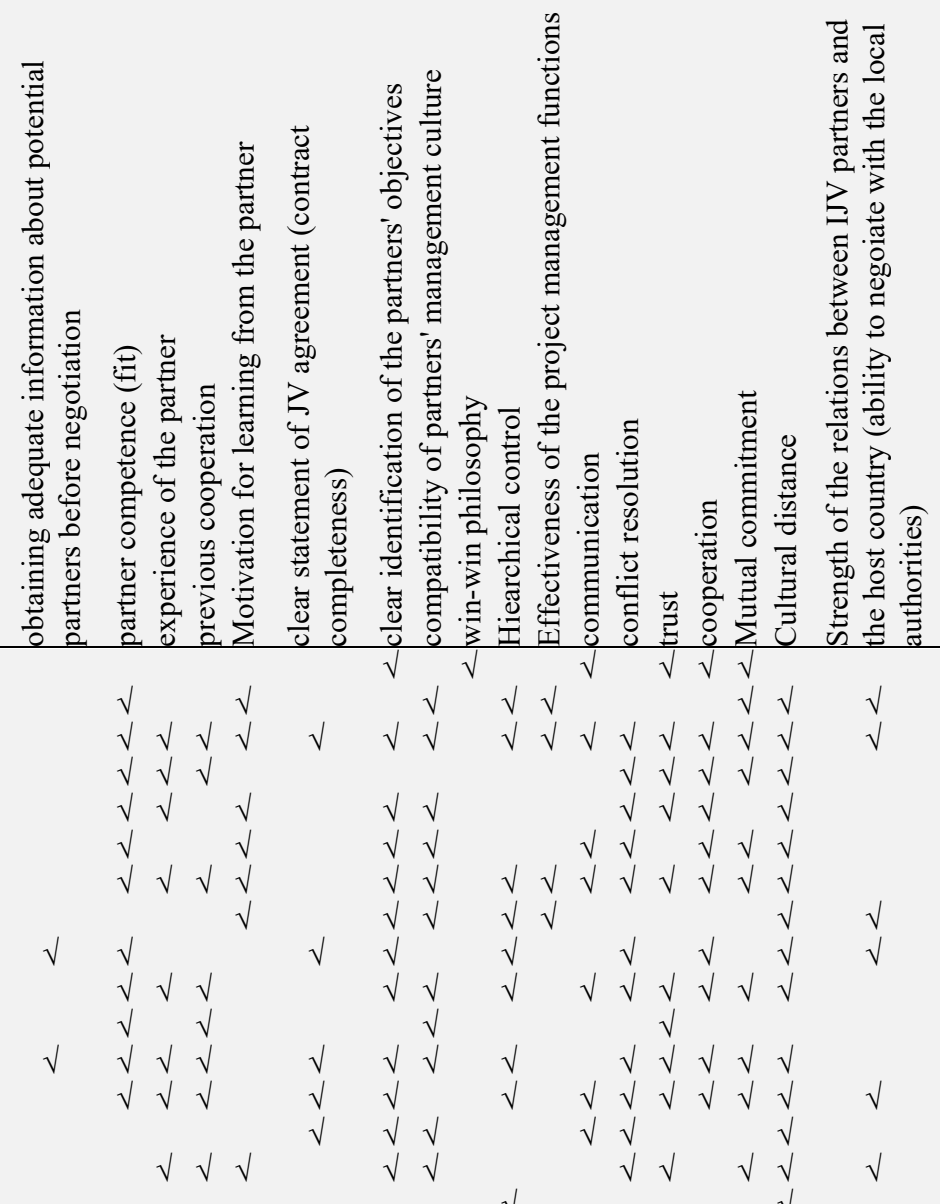

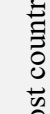

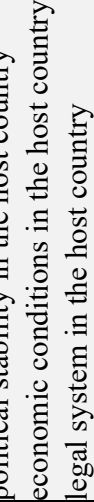

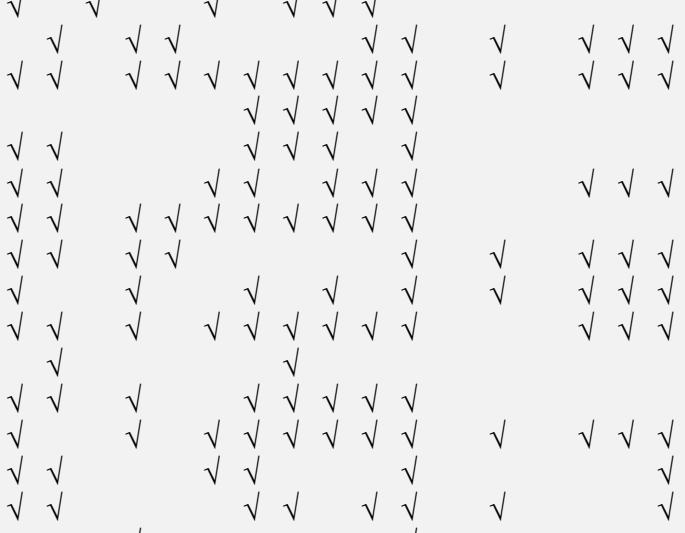

$\sqrt{ }$

$\begin{array}{lll}\sqrt{ } & \sqrt{ } & V\end{array}$

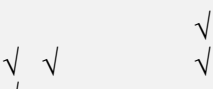

$\sqrt{ } \sqrt{ }$

$\sqrt{ }$
$\sqrt{ }$
$\sqrt{ }$
$\sqrt{ }$
$\sqrt{ }$
$\sqrt{ }$

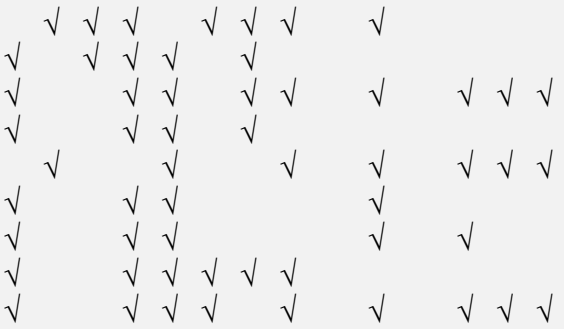

$\sqrt{ }$

$\sqrt{ } \sqrt{ } \sqrt{ } \sqrt{ }$

$$
\sqrt{ }
$$

$\sqrt{ }$

$\sqrt{ } \sqrt{ }$

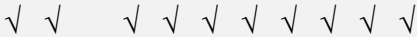

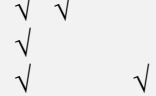

$\sqrt{ } \sqrt{ } \sqrt{ } \sqrt{ } \sqrt{ } \sqrt{ } \sqrt{ }$

$\sqrt{ }$

$\sqrt{ }$

$\begin{array}{lllllll}\sqrt{ } & \sqrt{ } & \sqrt{ } & \sqrt{ } & \sqrt{ } & \sqrt{ } & \sqrt{ }\end{array}$

$\sqrt{ } \sqrt{ } \sqrt{ } \sqrt{ } \sqrt{ }$

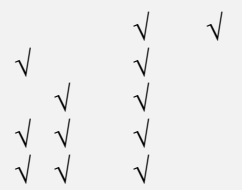

$\sqrt{ } \sqrt{ }$

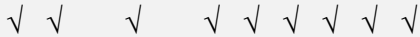

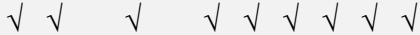

$\sqrt{ } \sqrt{ }$

$\sqrt{ }$

$\sqrt{ } \sqrt{ } \sqrt{ } \sqrt{ }$

$\sqrt{ } \quad \sqrt{ } \sqrt{ }$

$\sqrt{ } \sqrt{ }$ 
Table 2. Core elements of ICJVs (Aydogan [15])

\begin{tabular}{lc}
\hline Core components & Rankings \\
\hline Cultural distance & 30 \\
Conflict resolution & 30 \\
Trust & 28 \\
Clear identification of partners' goals & 27 \\
Hierarchical control & 26 \\
Mutual commitment & 25 \\
Partner competence & 24 \\
Compatibility of partners' management & 21 \\
culture & 21 \\
Cooperation & \\
\hline
\end{tabular}

Clear identification of partners' goals follows trust, since it has direct effects on cooperation, mutual commitment and the overall performance of ICJVs. In addition, partner competence has a high rate among other core components of ICJVs. The resources of each partner are vital for the success of the venture, since resource dependence is one of the main motivations of ICJVs. Thus, obtaining adequate information about potential partners is necessary at the beginning. This provides to make a proper selection among potential partners. Compatibility of partners' management culture has positive effects on the performance of ICJVs as the misunderstandings between partners decrease due to similarities of the organizations. Finally, cooperation has also found to be a core element of ICJVs that are partner related. Effective cooperation has positive effects on overcoming conflicts due to contractual constraints [39]. Selecting an appropriate partner with competence resources and compatible culture leads a wellintegrated group working for the sharing goals. Consequently, mutual commitment and effective cooperation are the outcomes of venturing with an appropriate partner.

\subsection{Core components of venture management related issues}

Within ICJVs, participating firms also share their responsibilities by functional separation and delegation of work [7]. That's why; venture management issues have effects on the overall performance of ICJVs. Effectiveness of project management functions has impacts on the success of ICJVs. Conflicts can rise due to miscommunication, differences in partners' management styles and incongruity of partners' goals. Conflict among partners tends to cause serious problems during construction phase which in turn results in delays and unexpected costs. Clear identification of partners' goals can decrease conflicts during venturing. Thus, conflict resolution techniques have vital importance on the performance of ICJVs. On the other hand; less participation in daily operational management has found to reduce the level of management control over IJVs even in equity share ventures [29]. That's why; hierarchical control is stated as another core component of venture management related issues. In addition, effectiveness of management functions highly related to the clear statement of IJV contract. The interaction of IJV contracts and cooperation of parties and how they jointly affect overall performance of IJVs is another topic in the literature [39]. It is also possible that the control of IJVs structure may change during operation phase due to changes of partner's resources [40]. In an example; when the foreign partner reaches a stable relationship with the host government, IJV control structure tends to change. Hence, the effects of unexpected changes in the local governments' policies on the IJVs control structure have also investigated by researchers [41].

\subsection{Core components of environmental related issues}

Environmental aspects have effects on the performance of international organizations and their profitability. Besides partner related issues and venture management related issues environmental related issues have effects on the overall performance of ICJVs. Core components of environmental related issues include risks due to; cultural distance, political stability in the host country, economic conditions in the host country, and legal system in the host country. Cultural differences lead miscommunication and 
misunderstandings during management process. These misunderstandings sometimes cause serious conflicts that affect the performance of a venture. Cultural differences can also tend to increase conflicts in setting up venture goals [42]. Regional government changes may have adverse effects on the overall performance of ICJVs. On-going construction projects may have postponed or cancelled due to regional governmental changes. On the other hand; internal or external conflicts are the other causes of cancellation of the on-going construction projects. Government policy to foreign contractors is also very important for international contractors. Bureaucracy and some restrictions in workforce and material supply and the taxes for foreign firms affect the performance of the project and the profitability of international contractors. Briefly; changes in government policy to construction sector or government changes would have serious effects on the performance of the project and the profit of the international business enterprise. Executives invest time and energy in building relationships with the new government officials due to unexpected government changes [43]. Since, management of claims, conflicts between partners and any contract related problems are regulated by the legal system in the host country, strength of the legal system in the host country is vital in the formation and operation of an ICJV [44]. On the other hand; opportunistic behaviour may arise due to lack of adequate legal protection since rule of law in the host country sets up and generates the organizational action and protects corporate activity [45].

Economic conditions in the host country may threat the profitability and other goals of an international business enterprise. That's why; economic risks affect the performance of ICJVs. In an example; high inflation rates has serious effects on the cost of a construction project [46, 47]. Besides, fluctuations in the exchange rates in the host country can cause financial and payment related risks of currency exposure for foreign investors [48, 49]. Cultural issues including; cultural fit of partners and cross-cultural management are the main topics of previous studies
$[5,25,26,50,51]$. Due to rankings of core elements of ICJVs; cultural differences has the highest ranking among all and the elements of environmental related issues.

\section{Analysing ICJVs by applying Wittgenstein's family-resemblance concept: The ICJV flower}

Based on the reviewed literature by Aydogan [15], "Cultural Distance", "Conflict Resolution", "Trust", "Clear identification of partners' goals", "Hierarchical Control", "Mutual Commitment", "Partner Competence", "Compatibility of Partners' Management Culture" and "Cooperation" were identified as the core components of ICJVs as they were cited with the highest frequencies by the authors (Table 2). The determined core components of ICJVs can be interpreted as vital, but not satisfactory in defining all ICJV cases, since some other components should also be taken into account depending on the diverse dynamics of each venture. Therefore, application of family-resemblance theory in defining ICJVs will be useful, since it is a way of defining a phenomenon not only a network of overlapping similarities but also concerning common features. Taking nine common features of ICJVs in to the centre, the rest of the components can be seen as petals when family-resemblance theory is used in defining ICJVs as shown in Fig. 1. From this point of view, it is obvious that nine core elements should be concerned in defining ICJVs where the existence of other elements that appear as petals depends on each case. The combination of petals differs due to the dynamics of each venture. Briefly, the flower as seen in Fig. 1 is the application of family-resemblance theory for defining the whole 'family' of all ICJV variants.

\section{Application of the Ludwig Wittgenstein's Family-Resemblance Concept}

A practical application of the somewhat vague concept of family-resemblance is as the structure mentioned-above in Figure 1. This structure allows various designs of ICJVs to be represented, which is indicated by the following cases. 


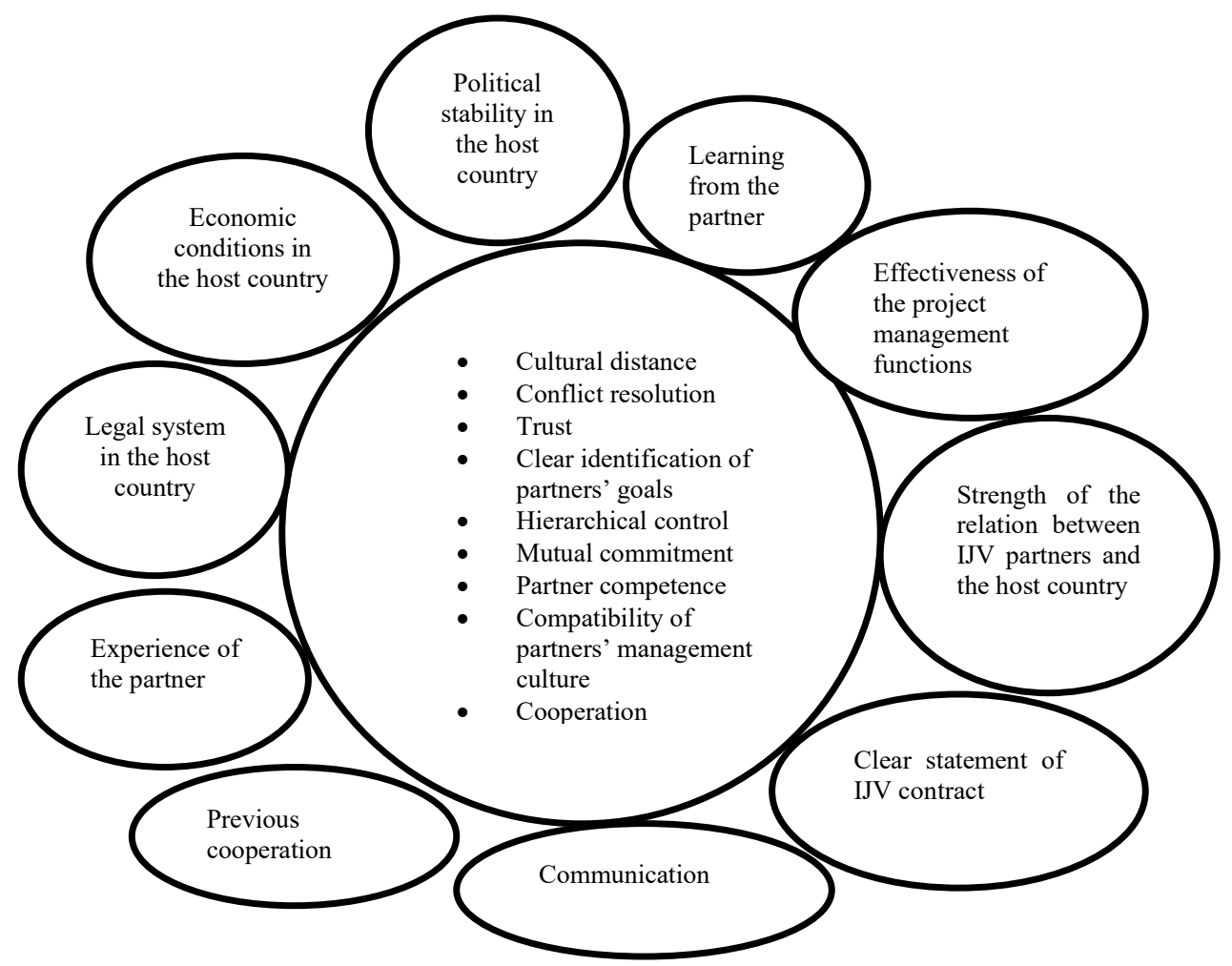

Fig. 1. ICJV Flower

These cases are the ICJVs that TAV Construction has evolved in. TAV Construction is a strategic partnering founded by Tepe and Akfen Group highly experienced in aviation projects in global arena. The evaluations of these cases were determined through a face to face interview with the CEO of TAV.

CASE 1: The first case is Riyadh King Khalid Airport Terminal 5 Project which was constructed by TAV-ACC (Al-Arrab Contracting Company) JV. Besides nine common core elements this ICJV included:

- Political stability in the host country

- Economic conditions in the host country

- Legal system in the host country

- Strength of the relation between IJV partner and government

- Previous cooperation

- Effective communication

- Clear statement of IJV contract
This variant of ICJV is described by the set of elements within the thin full line in Figure 2. The CEO of TAV has mentioned that reducing the effects of host country related risks and accessing local resources easily were the main motivations of this venture. Hence, environmental related elements of ICJVs and strength of the relation between IJV partners and government are concerned in defining ICJV for this venture. In addition to these components of ICJV, communication and clear statement of IJV contract are also added to the list, since the CEO of TAV has mentioned that problems due to miscommunication, distrust and delays in decision making process were the main challenges of this venture.

CASE 2: The second case is Paris-Charles de Gaulle Airport Management Buildings which was constructed by TAV- Hervé SA JV. Besides nine common core elements this ICJV included: 


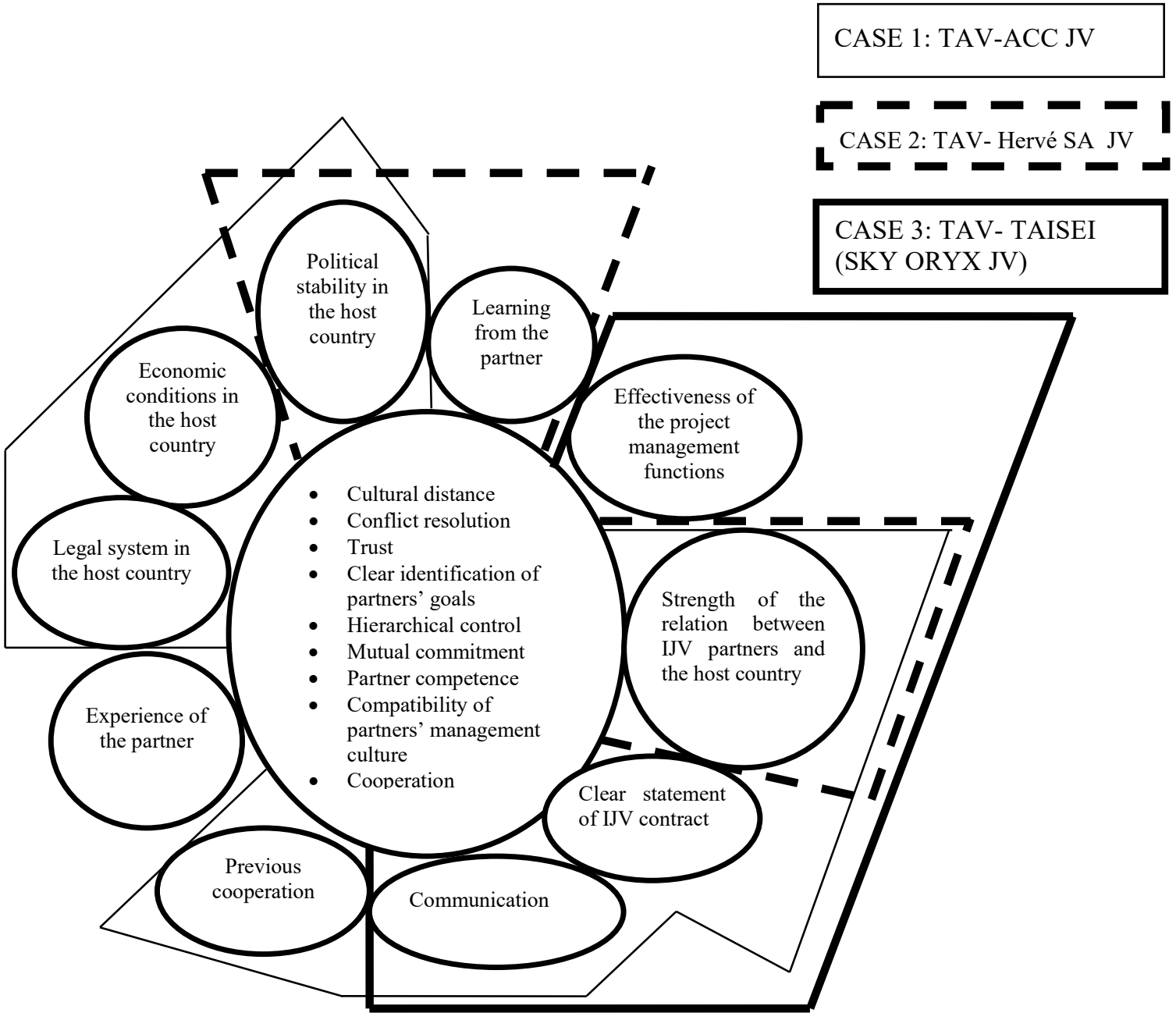

Fig. 2. The applied ICJV flower

- Political stability in the host country

- Strength of the relation between IJV partner and government

- Learning from the partner

The variant of ICJV is described by the set of elements within the thick dotted line in Figure 2. Increasing credibility during tendering and accessing local resources easily and technical know-how of the partner were mentioned as the main motivations of this venture by the CEO of TAV. Consequently, TAV has preferred to work with a local partner to increase credibility during tendering and to access local resources easily. TAV has selected a local partner with an appropriate technological knowledge since learning from the partner is one of the key components for this venture.

CASE 3: The third case is Qatar Hamad International Airport which was constructed by TAV- TAISEI. This venture was named as SKY ORYX JV. Giving a separate name to a venture makes the staff of each partner to work for the same goals as a team. The CEO of TAV has also mentioned the importance of integrity on the overall performance of ICJVs. Entering a new market, sharing project related risks, increasing credibility during tendering and accessing local resources easily, financial resources of the partner and technical know-how of the partner were mentioned 
as the main motivations of this venture. In addition to nine common core elements this ICJV included:

- Strength of the relation between IJV partner and government

- Effective venture management

- Clear statement of IJV contract

- Effective communication

This integrated variant of ICJV is described by the set of elements within the thick full line in Figure 2. TAV has preferred to work with a Japanese construction firm due to technical knowhow of TASEI and the good relations of Qatar and Japan. Consequently; strength of the relation between IJV partner and government is concerned in defining ICJV for this project. Cultural differences, miscommunication and distrust have been mentioned as the prominent challenges of this venture. Hence, effective venture management, clear statement of IJV contract and effective communication have also been concerned in defining ICJV for this venture.

\section{Conclusions}

There are two contributions in this study. First, it is concluded that the specific components are compelling when grasping what is unique about international venturing. The second contribution consists of stating ICJV as a complex concept which is difficult to define in the traditional way by giving necessary and sufficient conditions. Instead, Wittgenstein's Family Resemblance approach is suggested, where it is possible to understand a concept by looking for a network of overlapping similarities. Wittgenstein's family resemblance approach is an appropriate tool in making definitions of complex concepts depending on a network of overlapping similarities. By applying Wittgenstein's idea of family resemblance, an ICJV Sunflower Model has been proposed within this study. In order to develop the sunflower representing the ICJV, the core components of ICJVs were identified based on a previous study related to an intensive literature review. 'Cultural Distance', 'Conflict Resolution', 'Trust', 'Clear identification of partners' goals', 'Hierarchical Control', 'Mutual Commitment', 'Partner
Competence', 'Compatibility of Partners' Management Culture' and 'Cooperation' were identified as the core elements of ICJVs. Besides these nine core elements, there was an overlapping network of the other elements.

The sunflower model applied to three cases in order to define ICJVs. It is obvious that besides the core components, the rest of the components vary due to project related and environmental related issues. In other words; the petals of the flower can be arranged in any number of combinations. The sunflower model enables a framework to define the vague concept of ICJVs in a more structured manner. However, there are some limitations in this study. Firstly, the sunflower model applied to three aviation projects that were undertaken by ICJVs. In addition, the sunflower of each case was adopted with the response of the same partner. The relation of each component with others can be discussed on a more theoretical approach in a further research. The ICJV flower can also be useful for practitioners in the formation phase of ventures, to identify the core components of the venture and to analyse the structure of the venture concerning other components of each case. This will help partners to have a common point of view on how to frame a specific venture in the formation phase of venturing.

\section{Declaration of conflicting interests}

The author(s) declared no potential conflicts of interest with respect to the research, authorship, and/or publication of this article.

\section{Acknowledgments}

I would like to thank Mr. Sani ŞENER -CEO of TAV for his remarkable contributions to this study.

\section{References}

[1] Gundes S, Aydogan G (2016) Bibliometric analysis of research in international construction. Canadian Journal of Civil Engineering, 43(4): 304-311.

[2] Child J (2002) A configurational analysis of international joint ventures. Organization Studies, 23(5): 781-815. 
[3] Das TK, Teng B-S (2000) Instabilities of strategic alliances: an internal tensions perspective. Organization Science, 1181): 77-101.

[4] Hyder AS, Ghauri PN (2000) Managing international joint venture relationships. Industrial Marketing Management, 29(3): 205-218.

[5] Chan EHW, Tse RYC (2003) Cultural considerations in international construction contracts. Journal of Construction Engineering and Management, 129(4): 375-381.

[6] Mohamed S (2003) Performance in international construction joint ventures: modeling perspective. Journal of Construction Engineering and Management, 129(6): 619-626.

[7] Girmscheid G, Brockmann C (2010) Inter- and intraorganizational trust in international construction joint ventures. Journal of Construction Engineering and Management. doi:10.1061/(asce)co.1943-7862.0000142

[8] Cheng EWL, Li H, Love PED, Irani Z (2004) Strategic alliances: A model for establishing longterm commitment to inter-organizational relations in construction. Building and Environment, 39(4): 459-468.

[9] Ping Ho S, Lin YH, Wu HL, Chu W (2009) Empirical test of a model for organizational governance structure choices in construction joint ventures. Construction Management and Economics, 27(3): 315-324.

[10] Ozorhon B, Arditi D, Dikmen I, Birgonul MT (2010) Toward a multidimensional performance measure for international joint ventures in construction. Journal of Construction Engineering and Management, 137(6): 403-411.

[11] Geringer JM. Joint Venture Partner Selection: Strategies for Developing Countries. Quorum, New York, 1988.

[12] Geringer JM, Hebert L (1989) Control and performance of international joint ventures. Journal of International Business Studies, 2082): 235-254.

[13] Chen C, Messner JI (2009) Entry mode taxonomy for international construction markets. Journal of Management in Engineering, 25(1): 3-11.

[14] Norwood SR, Mansfield NR (1999) Joint venture issues concerning European and Asian construction markets of the 1990's. Int J Proj Manag. https://doi.org/10.1016/S0263-7863(98)00016-7

[15] Aydogan G (2018) Performance characteristics of international joint ventures in construction. Eurasian Journal of Civil Engineering and Architecture, 2: 86-96.
[16] Kenyy A. Wittgenstein, Pelican Books, Harmondsworth, 1982.

[17] Murphy MA (1991) No more what is communication? Communication Research, 18: $825-835$.

[18] Nyström J (2005) The definition of partnering as a Wittgenstein family-resemblance concept. Construction Management and Economics, 23(5): 473-481.

[19] Yeung JFY, Chan APC, Chan DWM (2007) The definition of alliancing in construction as a Wittgenstein family-resemblance concept. International Journal of Project Management, 25(3): 219-231.

[20] Yeung JFY, Chan APC, Chan DWM (2012) Defining relational contracting from the Wittgenstein family-resemblance philosophy. International Journal of Project Management, 30(2): 225-239.

[21] Bing L, Tiong RLK (1999) Risk management model for international construction joint ventures. Journal of Construction Engineering and Management, 125(5): 377-384.

[22] Bing L, Tiong RL-K, Fan WW, Chew DA-S (1999) Risk management in international construction joint ventures. Journal of Construction Engineering and Management, 125(4): 277-284.

[23] Shen LY, Wu GWC, Ng CSK (2001) Risk assessment for construction joint ventures in china. Journal of Construction Engineering and Management, 127(1):76-81.

[24] Zhao X, Hwang BG, Yu GS (2013) Identifying the critical risks in underground rail international construction joint ventures: Case study of Singapore. International Journal of Project Management, 31(4): 554-566.

[25] Pheng LS, Leong CHY (2000) Cross-cultural project management for international construction in China. International Journal of Project Management, 18(5): 307-316.

[26] Ozorhon B, Arditi D, Dikmen I, Birgonul MT (2008) Implications of culture in the performance of international construction joint ventures. Journal of Construction Engineering and Management, 134(5): 361-375.

[27] London K, Siva JPS (2011) The role of reflexive capability in relation to intellectual capital on multi international partnerships. International Journal of Project Management, 29(7): 846-855.

[28] Lin Y-H, Ho SP (2013) Impacts of governance structure strategies on the performance of 
construction joint ventures. Journal of Construction Engineering and Management, 139: 304-311.

[29] Luo J (2001) Assessing management and performance of Sinoforeign construction joint ventures. Construction Management and Economics, 19(1): 109-117.

[30] Ozorhon B, Arditi D, Dikmen I, Birgonul MT (2010) Performance of international joint ventures in construction. Journal of Management in Engineering. https://doi.org/10.1061/(asce)me.19435479.00000 22

[31] Gale A, Luo J (2004) Factors affecting construction joint ventures in China. International Journal of Project Management, 22(1): 33-42.

[32] Sillars DN, Kangari R (2004) Predicting organizational success within a project-based joint venture alliance. Journal of Construction Engineering and Management,13084): 500-508.

[33] Ozorhon B, Dikmen I, Birgonul MT (2007) Using analytic network process to predict the performance of international construction joint ventures. Journal of Management in Engineering, 23(3): 156-163.

[34] Walker DHT, Johannes DS (2003) Construction industry joint venture behavior in Hong Kong Designed for collaborative results? International Journal of Project Management, 21(1): 39-49.

[35] Aydogan G, Koksal A (2013) An analysis of international construction risk factors on partner selection by applying ANP approach. International Conference on Construction and Real Estate Management, ICCREM 2013.

[36] Ranjay Gulati (1995) Does familiarity breed trust? the implications of repeated ties for contractual choice in alliances. Management Journal, 38(1): 85-112.

[37] Das TK, Teng BS (2001) Trust, control, and risk in strategic alliances: an integrated framework. Organization Studies, 22(2): 251-283.

[38] Cullen JB, Johnson JL, Sakano T (2000) Success through commitment and trust: the soft side of strategic alliance management. Journal of World Business, 35(3): 223-240.

[39] Luo Y (2002) Contract, cooperation, and performance in international joint ventures. Strategic Management Journal, 23(10): 903-919.

[40] Blodgett LL (1992) Research notes and communications factors in the instability of international joint ventures: An event history analysis. Strategic Management Journal, 13(6): 475-481.
[41] Yan A, Gray B (1994) Bargaining Power, Management Control, and Performance in United States-China Joint Ventures: A Comparative Case Study. Management Journal, 37(6): 1478-1517.

[42] Reus T, Rottig D (2009) Meta-analyses of international joint venture performance determinants: Evidence for theory, methodological artifacts and the unique context of China. Management International Review, 49(5): $607-$ 640.

[43] Oetzel J (2005) Smaller may be beautiful but is it more risky? Assessing and managing political and economic risk in Costa Rica. International Business Review, 14(6): 765-790.

[44] Ozorhon B, Arditi D, Dikmen I, Birgonul MT (2007) Effect of host country and project conditions in international construction joint ventures. International Journal of Project Management, 25(8): 799-806.

[45] Luo Y (1997) Partner selection and venturing success: The case of joint ventures with firms in the People's Republic of China. Organization Science 8(6): 648-662.

[46] Gunhan S, Arditi D (2005) Factors affecting international construction. Journal of Construction Engineering and Management, 131(3): 273-281.

[47] Zhi H (1995) Risk management for overseas construction projects. International Journal of Project Management, 13(4): 231-237.

[48] Hastak M, Shaked A (2002) ICRAM-1: Model for International Construction Risk Assessment. Journal of Management in Engineering, 16(1): 5969.

[49] Han, S.H. and Diekmann JE (2001) Approaches for making risk-based go/no go decision for international projects. Journal of Construction Engineering and Management, 127: 300-308.

[50] Tone K, Skitmore M, Wong JKW (2009) An investigation of the impact of cross-cultural communication on the management of construction projects in Samoa. Construction Management and Economics, 27(4): 343-361.

[51] Ochieng EG, Price ADF (2010) Managing crosscultural communication in multicultural construction project teams: The case of Kenya and UK. International Journal of Project Management, 28(5): 449-460. 